\title{
Outcomes of surgical repair of pediatric coronary artery fistulas
}

Wen Zhang, MD, Renjie Hu, MD, Lei Zhang, MD, Hongbin Zhu, MD, and Haibo Zhang, MD, PhD

\section{ABSTRACT}

Objective: Isolated congenital coronary artery fistula is a rare condition, and the surgical experience for treating this condition is limited.

Methods: This was a retrospective review of 47 patients who underwent surgical repair of isolated congenital coronary artery fistula from January 2001 to March 2015.

Results: All but 1 patient presented with no symptoms. The median age at operation was 3.9 years (range, 0.4-15.2 years), and the median weight was $15.2 \mathrm{~kg}$ (range, $6.3-77.0 \mathrm{~kg}$ ). Right coronary artery to right ventricle fistula was the most common pattern, which was present in 16 patients. Epicardial ligation without cardiopulmonary bypass was used to treat 4 patients, whereas cardiopulmonary bypass was used in the remaining 43 patients. Surgical techniques included transcoronary closure in 20 patients, transcameral or transpulmonary closure in 20 patients, a combination of both transcameral and transcoronary closure in 2 patients, and a conversion from transcameral closure to epicardial ligation in 1 patient. There were no deaths during our study period. Injury to the mitral valve occurred in 1 patient. Residual shunt was observed in 8 patients, 2 of which closed spontaneously during the follow-up. Extracardiac repair was associated with a higher risk of recanalization $(P=.004)$. Freedom from recanalization was $89.4 \%, 85.1 \%, 83.0 \%$, and $83.0 \%$ at discharge, 6 months, 1 year, and 5 years postsurgery, respectively. Two patients required transcatheter closure for residual shunts.

Conclusions: Surgical repair of isolated congenital coronary artery fistula in pediatric patients can be performed with low mortality and morbidity. Careful evaluation after surgery is necessary to monitor the occurrence of residual shunt. (J Thorac Cardiovasc Surg 2016;152:1123-30)

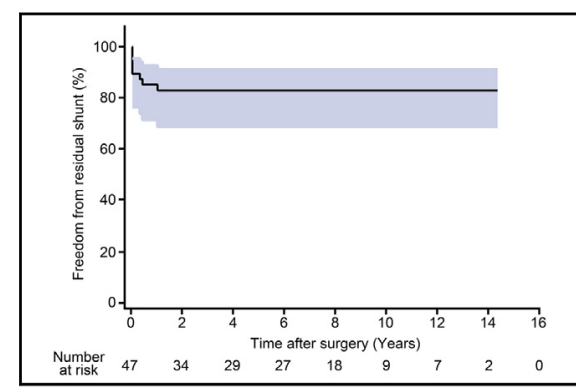

Freedom from residual shunt after surgical repair is shown.

\section{Central Message}

Surgical repair of ICCAF in the pediatric population is safe, but caution should be taken to monitor any residual shunts.

\section{Perspective}

The management of ICCAF in the pediatric population is subject to continuing debate, especially among asymptomatic patients. Our experience with 47 patients showed that surgical repair for ICCAF can be performed safely with low mortality and morbidity. Residual shunt is more likely to occur after extracardiac repair. Therefore, careful evaluation during the follow-up period is a necessity.

See Editorial Commentary page 1131.
Coronary artery fistulas (CAFs) are defined as an abnormal connection between a coronary artery and a cardiac chamber or great vessel. CAFs are relatively rare, accounting for only $0.2 \%$ of pediatric patients undergoing diagnostic coronary angiography. ${ }^{1} \mathrm{CAF}$ can be an isolated lesion or associated with other congenital heart defects, such as

\footnotetext{
From the Department of Cardiothoracic Surgery, Shanghai Children's Medical Center, Shanghai Jiaotong University School of Medicine, Shanghai, China.

Received for publication Dec 8, 2015; revisions received March 30, 2016; accepted for publication April 30, 2016; available ahead of print May 28, 2016.

Address for reprints: Haibo Zhang, MD, PhD, Department of Pediatric Cardiothoracic Surgery, Shanghai Children's Medical Center, Shanghai Jiaotong

University School of Medicine, 1678 Dongfang Rd, Shanghai, China (E-mail: zhanghaibosh@126.com).

$0022-5223 / \$ 36.00$

Copyright (c) 2016 by The American Association for Thoracic Surgery

http://dx.doi.org/10.1016/j.jtcvs.2016.04.093
}

pulmonary atresia with intact ventricular septum, tetralogy of Fallot, atrial septal defect, ventricular septal defect, and patent ductus arteriosus. Isolated congenital coronary artery fistulas (ICCAFs) in pediatric patients are usually asymptomatic. Because the natural history of the fistula is poorly defined, management techniques are controversial and based on institutional preferences. The aim of the current study is to review our surgical experience and to evaluate the mid- to long-term outcomes for the surgical repair of ICCAFs.

Scanning this QR code will take you a video and supplemental figure for the article. 


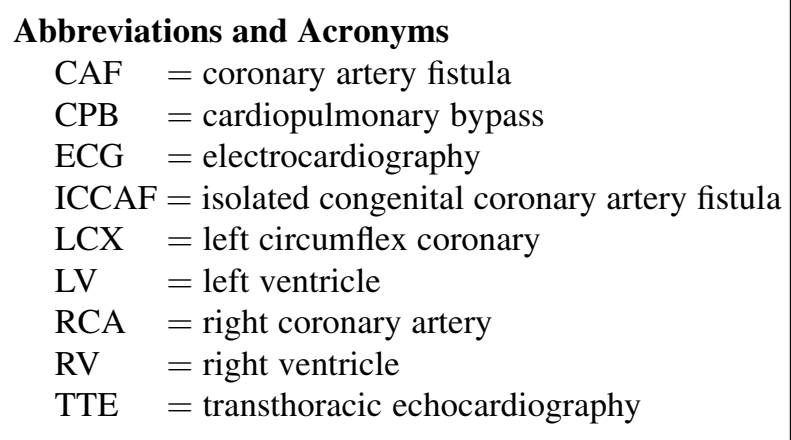

\section{PATIENTS AND METHODS}

The Ethics Committee of Shanghai Children's Medical Center approved this study.

\section{Preoperative Characteristics}

Between January 2001 and March 2015, 47 consecutive patients underwent surgical repair of ICCAFs at the Shanghai Children's Medical Center. Patients were asymptomatic and presented with a cardiac murmur on auscultation, with the exception of one 15-year-old patient with palpitations. Seventeen patients $(36.3 \%)$ were diagnosed during infancy, but 12 of them $(70.6 \%)$ did not undergo immediate surgery. The median age at repair was 3.9 years (range, 0.4-15.2 years), and the median weight was $15.2 \mathrm{~kg}$ (range, $6.3-77.0 \mathrm{~kg}$ ). Among them, 30 were male $(63.8 \%)$ and 17 were female $(36.2 \%)$. No patients had undergone any previous surgical interventions.

The diagnosis of ICCAF was made mainly by transthoracic echocardiography (TTE). Since 2013, multidetector computed tomography with a reconstruction technique has been widely performed within our department as a noninvasive diagnostic technique (Figure E1). The origin and the drainage site of the fistula varied (Table 1). The most common origin was the right coronary artery (RCA) in 28 patients $(59.6 \%)$, and the most common site of drainage was the right ventricle (RV) in 23 patients $(48.9 \%)$. The RCA to RV fistula was the most common pattern (16 patients, $34.0 \%)$. Multiple fistulas were identified in 9 patients $(19.1 \%)$; the fistula drained into both the RV and the pulmonary artery in 2 patients $(4.3 \%)$.

Preoperative electrocardiography (ECG) data revealed left ventricular hypertrophy in 10 patients $(21.3 \%)$, right ventricular hypertrophy in 1 patient $(2.1 \%)$, and biventricular hypertrophy in 1 patient $(2.1 \%)$. ST-T changes were observed in 11 patients $(23.4 \%)$.

Dilation of the feeding coronary artery was observed in all patients with an 8.6- $\mathrm{mm}$ median dimension (range, $2.8-25.5 \mathrm{~mm}$ ) of the coronary origin. The median dimension of the fistula was $4.7 \mathrm{~mm}$ (range, $2.5-15.4 \mathrm{~mm}$ ). Tricuspid regurgitation secondary to volume overload was mild in 5 patients $(10.6 \%)$, trivial in 35 patients $(74.5 \%)$, and negative in 7 patients $(14.9 \%)$.

Cardiac catheterization and coronary angiography were performed in 37 patients $(78.7 \%)$. Major anatomic characteristics included coronary artery branch arising near the drainage site (22 patients) (Figure 1, A), extremely tortuous feeding coronary artery (7 patients) (Figure 1, B), multiple or diffuse drainage sites (6 patients) (Figure 1,C), and aneurysmal dilation of the feeding coronary artery (2 patients) (Figure 1, $D$ ). During cardiac catheterization, the attempt to close the fistula failed in 1 patient. She was a 3-year-old girl with a dilated RCA. A branch of the RCA was tortuous and drained into the RV outflow tract. The occlusion test was accompanied by an ST-T change on ECG monitoring. Therefore, the patient was transferred to our department for surgery 1 week later.
TABLE 1. Anatomic characteristics of the isolated congenital coronary artery fistula

\begin{tabular}{lr}
\hline & $\mathbf{n}(\%)$ \\
\hline Origin site & \\
Unilateral & \\
RCA & $28(59.6)$ \\
LCX & $12(25.5)$ \\
LAD & $5(10.6)$ \\
Bilateral & \\
LAD + RCA & $2(4.3)$ \\
Drainage site & \\
RV & $23(48.9)$ \\
RA & $10(21.3)$ \\
LV & $10(21.3)$ \\
RV + PA & $2(4.3)$ \\
LA & $1(2.1)$ \\
PA & $1(2.1)$ \\
\hline
\end{tabular}

$R C A$, Right coronary artery; $L C X$, left circumflex artery; $L A D$, left anterior descending; $R V$, right ventricle; $R A$, right atrium; $L V$, left ventricle; $P A$, pulmonary artery; $L A$, left atrium.

\section{Surgical Technique}

Surgery was performed through a median sternotomy. Epicardial ligation of the fistula without cardiopulmonary bypass (CPB) was performed in 4 patients $(8.5 \%)$. CPB was used in the remaining 43 patients $(91.5 \%)$. A transcoronary approach was applied in 20 patients $(42.6 \%), 2(4.3 \%)$ of whom underwent concomitant arterioplasty to remove the excess aneurysm wall. Transcameral or transpulmonary approach was applied in 20 patients $(42.6 \%)$ to close the fistula from inside (Figure 2 and Video 1). Two patients $(4.3 \%)$ underwent combined extra- and intracardiac repairs to ensure successful obliteration. The initial attempt to close the fistula inside the left ventricle (LV) failed in 1 patient $(2.1 \%)$ and was converted to an epicardial ligation. Five infants underwent surgical obliteration, via a transcoronary approach in 1 and via a transcameral approach in 4 . The median time for CPB was 42 minutes (range, 20-222 minutes), and the median time for crossclamp of the aorta was 24 minutes (range, 10-148 minutes).

Obliteration of the fistula was achieved by direct suture (24 patients, $51.1 \%$ ) or patch closure (23 patients, $48.9 \%$ ). Patch materials included autologous pericardial patch in 15 patients $(65.2 \%)$, Dacron (DuPont, Wilmington, Del) in 6 patients $(26.1 \%)$, and polytetrafluoroethylene (Gore-Tex; WL Gore and Associates, Flagstaff, Ariz) in 2 patients $(8.7 \%)$.

\section{Follow-up}

Patients were followed 1 month, 3 months, and 6 months after discharge, then every 6 months for the next 18 months, and then regularly every 12 months. Postoperative medical records and test reports, including TTE and ECG, were collected during the follow-up. Because the Shanghai Children's Medical Center is exclusively a pediatric institution, 6 patients $(12.8 \%)$ were not followed up as they reached adulthood. Therefore, attempts were made to obtain the data through telephone calls. The median follow-up time was 7.8 years (range, 0.8 14.3 years).

\section{Statistical Analysis}

Data were analyzed with SPSS software, version 20.0 (SPSS Inc, Chicago, Ill). Continuous variables are presented as mean \pm standard deviation or median and range for skewness variables. Categoric variables are expressed as frequency and percentages and compared using the Fisher 

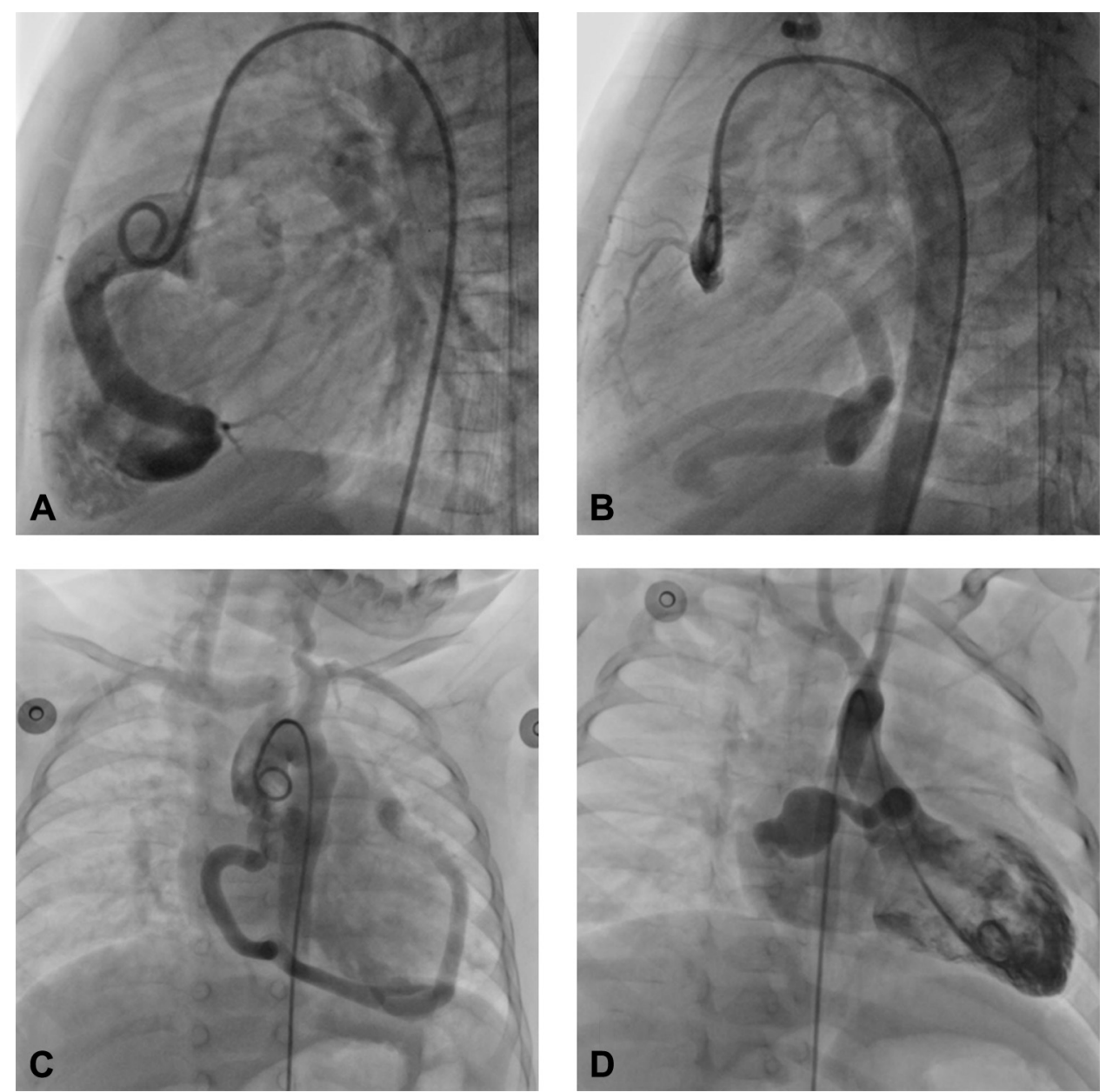

FIGURE 1. Catheter angiography demonstrating anatomic characteristics of the CAF. A, RCA is enlarged and gives rise to branches before terminates at the RV. B, LCX is extremely tortuous along its route to the RV. C, Fistula from both RCA and LCA to RV. The drainage sites of both fistulae are very close to each other. D, RCA is enlarged with an aneurysm at the middle portion.

exact test. Kaplan-Meier analysis was used to evaluate the freedom from recanalization.

\section{RESULTS}

The median time for postoperative mechanical ventilation was 5 hours (range, 1-71 hours), and the median time for an intensive care unit stay was 2 days (range, 1-5 days). No early or late mortality occurred throughout our study period. All the patients were in good cardiac condition (New York Heart Association functional class I). Thirteen patients $(27.7 \%)$ experienced transient ST-T changes after surgery, 6 after the transcoronary approach and 7 after the transcameral approach. However, no patients experienced transient ST-T changes after epicardial ligation. No evidence of wall motion abnormalities was identified on echocardiogram. No additional intervention was performed. All conditions resolved in patients at the time of discharge and remained negative during follow-up.
Injury to the mitral valve occurred in 1 patient $(2.1 \%)$ with an RCA to the LV fistula. The opening of the fistula beneath the posterior leaflet of the mitral valve was diffuse, and no obvious exit point could be clearly identified. The flow to the aorta was compromised after the initial attempt to close the fistula with an autologous pericardial patch. Therefore, CPB was applied once again to detach the patch. An epicardial ligation of the dilated coronary artery was then performed at the base of the heart. Concomitant annuloplasty was performed to repair the mitral valve. Mild mitral regurgitation was identified by echocardiography after surgery.

Residual shunt occurred in 8 patients (17.0\%) (Table 2), including 1 infant. Five $(10.6 \%)$ of these shunts occurred immediately after surgery with a median diameter of $1.9 \mathrm{~mm}$ (range, 1.4-2.9 mm). No reoperation was performed before discharge. Residual shunt was detected in another 3 patients $(6.4 \%)$ during the follow-up period. 

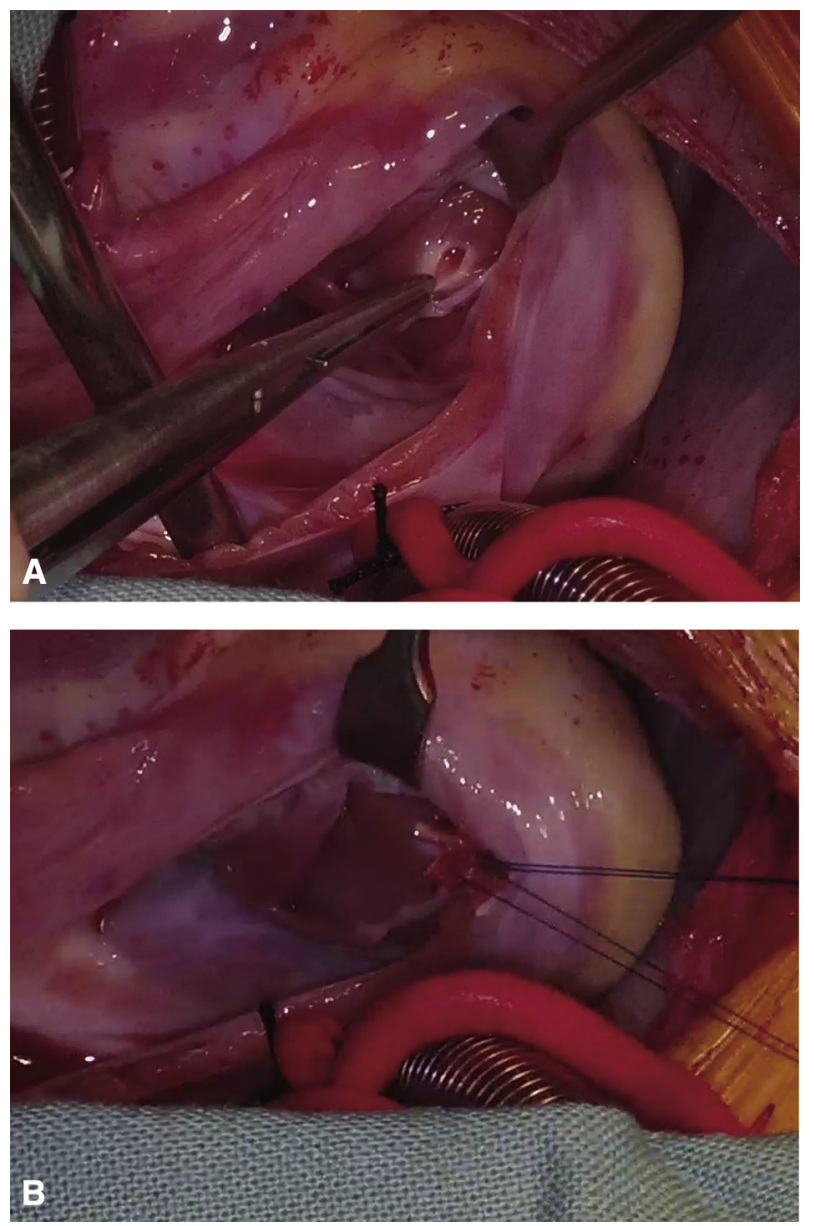

FIGURE 2. Intraoperative images showing the transcameral closure technique. A, Identification of the fistula orifice inside the RV through the right atrium and tricuspid valve. B, The fistula is closed by suture ligation with pads.

Freedom from residual shunt was $89.4 \%, 85.1 \%, 83.0 \%$, and $83.0 \%$, at discharge, 6 months, 1 year, and 5 years postsurgery, respectively (Figure 3). These patients remained asymptomatic without any complications during our study period. All 8 patients with residual shunts underwent initial extracardiac repair of the fistula only (epicardial ligation in 3 patients and transcoronary approach in 5 patients). There was a significant difference between patients who underwent extracardiac repair only and patients who underwent intracardiac repair in terms of the occurrence of the residual shunt $(32.0 \%$ vs $0 \%, P=.004)$, whereas no significant difference was identified between direct ligation and patch closure $(12.5 \%$ vs $21.7 \%$, $P=.461)$. No any other predictors of residual shunts could be identified.

The residual shunt closed spontaneously in 2 patients, one at 3 and another at 5 months after discharge. Reintervention for obliteration of the residual shunt was

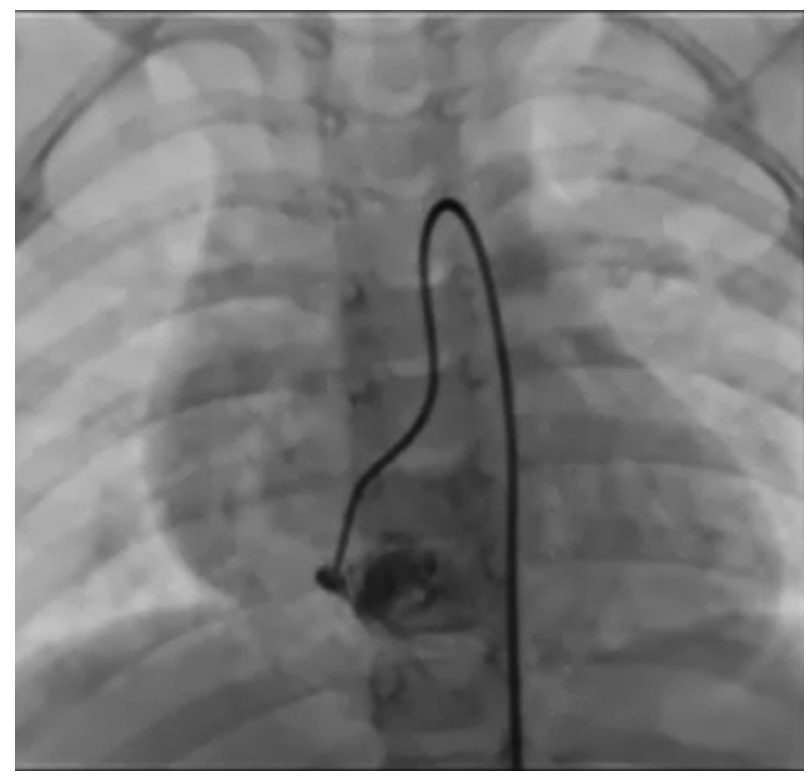

VIDEO 1. Transcameral closure of CAF. This was a 3-year-old boy with an RCA to RV fistula. Preoperative cardiac catheterization demonstrated that the RCA gave rise to small branches before terminating at the RV. Transcameral closure of the fistula was performed via a median sternotomy. CPB was performed via aortobicaval cannulation. Aortic crossclamping and cardioplegia were used. The fistula orifice was identified by RV exposure through the right atrium and tricuspid valve. The fistula was confirmed by delivery of cardioplegic solution. The fistula was closed by direct suture with pads. Successful closure was confirmed by administering methylene blue in cardioplegia. No residual shunt was identified on intraoperative transesophageal echocardiography. Video available at http://www.jtcvsonline.org/article/ S0022-5223(16)30314-2/addons.

performed in 2 patients $(4.3 \%)$ via percutaneous closure. The first patient was a boy who underwent transcoronary repair for a left anterior descending artery to RV fistula initially at the age of 4 years. Postoperative TTE showed a residual shunt with a width of $1.9 \mathrm{~mm}$. The shunt increased to $2.3 \mathrm{~mm}$ in diameter after 4 years of follow-up. Two aneurysms, with diameters of $24.8 \mathrm{~mm}$ and $18.6 \mathrm{~mm}$, were identified and connected by an isthmus coronary portion (Figure 4, A). Because the fistula drained into the apex of the RV, an Amplatzer PDA occluder (AGA Medical Corp, Golden Valley, Minn) was placed between the aneurysms. Postoperative angiography revealed a successful closure (Figure 4, B). The second patient was a 4-month-old boy with a left circumflex coronary (LCX) artery to RV fistula who also underwent initial transcoronary repair. The postoperative residual shunt was $2.9 \mathrm{~mm}$ wide. Reintervention was performed 1 year later when the diameter reached $3.3 \mathrm{~mm}$. A branch of coronary artery was dilated to $12 \mathrm{~mm}$ proximal to the drained fistula (Figure 4,C). Therefore, an occlusion was made with a 12-mm 
TABLE 2. Characteristics of 8 patients with postoperative residual shunts

\begin{tabular}{|c|c|c|c|c|c|c|c|}
\hline $\begin{array}{c}\text { Patient } \\
\text { no. }\end{array}$ & $\begin{array}{c}\text { Age at } \\
\text { surgery }(y)\end{array}$ & Origin site & $\begin{array}{l}\text { Drainage } \\
\text { site }\end{array}$ & Surgical technique & $\begin{array}{c}\text { Time of recanalization } \\
\text { after surgery }(\mathbf{y})\end{array}$ & $\begin{array}{l}\text { Diameter of the initial } \\
\text { residual shunt }(\mathrm{mm})\end{array}$ & Outcome \\
\hline 1 & 10.4 & RCA & RV & Transcoronary & 1.0 & Trivial & $\mathrm{SC}$ \\
\hline 2 & 4.8 & LCX & LV & Transcoronary & IS & 1.4 & $\mathrm{SC}$ \\
\hline 3 & 4.7 & LAD & $\mathrm{RV}$ & Transcoronary & IS & 1.9 & $\mathrm{TC}$ \\
\hline 4 & 5.6 & RCA & LV & Transcoronary & IS & 1.7 & $\mathrm{CF}$ \\
\hline 5 & 5.9 & RCA & LV & Transcoronary & IS & 2.1 & $\mathrm{CF}$ \\
\hline 6 & 1.1 & $\mathrm{RCA}+\mathrm{LAD}$ & $\mathrm{RV}$ & Epicardial ligation & 0.3 & 2.5 & $\mathrm{CF}$ \\
\hline 7 & 4.4 & LAD & RV & Epicardial ligation & 0.6 & 1.7 & $\mathrm{CF}$ \\
\hline 8 & 0.4 & LCX & $\mathrm{RV}$ & Transcoronary & IS & 2.9 & $\mathrm{TC}$ \\
\hline
\end{tabular}

$R C A$, Right coronary artery; $R V$, right ventricle; $S C$, spontaneous closure; $L C X$, left circumflex artery; $L V$, left ventricle; $I S$, immediately after surgery; $L A D$, left anterior descending; $T C$, transcatheter closure; $C F$, continued follow-up.

Amplatzer vascular plug (AGA Medical Corp) (Figure 4, $D$ ). Postoperative TTE revealed a trivial leak, but no shunt was present 1 month later.

\section{DISCUSSION}

The first surgical closure of a CAF was reported by Biorck and Crafoord in $1947 .{ }^{2}$ The goal of the surgery is to close the fistula without compromising normal coronary flow to the rest of myocardium. Although the recommendation for patients with symptomatic CAF has always been to repair early, particularly when associated with other congenital heart defects, no consensus currently exists for asymptomatic fistulas or isolated CAFs, neither as far the timing of intervention nor whether the patient should undergo surgery. As for infants and children, surgical experience is limited and most published series are relatively small (Table 3). To our knowledge, our series is one of the largest pediatric ICCAF populations, and our results show that the surgical outcomes for ICCAF are largely satisfactory, although postoperative occurrence of the residual shunt should be carefully evaluated.

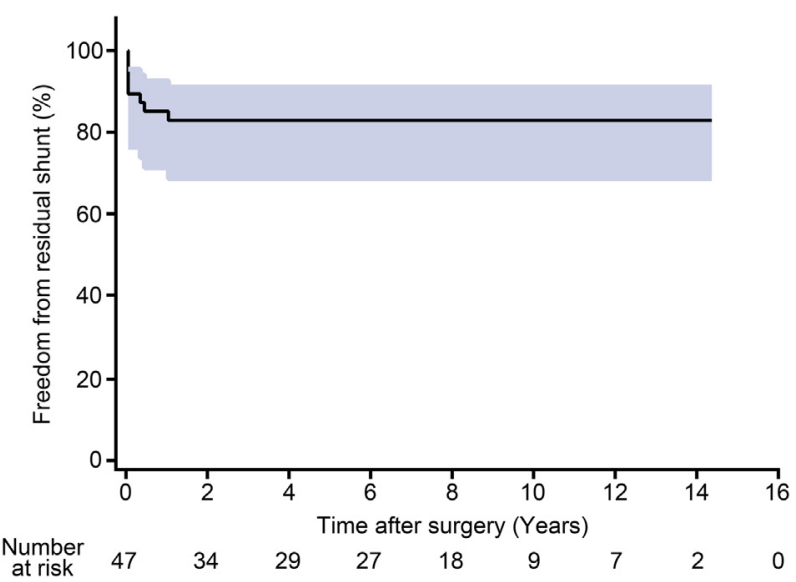

FIGURE 3. Kaplan-Meier analysis of the incidence of freedom from residual shunt after surgery. The shaded area indicates $95 \%$ confidence limits.
Congenital CAFs are believed to be caused by the persistence of embryonic intramyocardial trabecular sinusoids. $^{7}$ Most fistulas originate from the RCA, with the LCX being the second most common site of origin $(25.5 \%)$, which is in contrast to some surgical series claiming that fistulas rarely arise from the LCX. ${ }^{8,9}$ The drainage site usually is observed within the right heart structures, which is due to lower pressures $(76.6 \%$ in our experience).

Most ICCAFs in pediatric patients are diagnosed by the incidental finding of a cardiac murmur. The natural history of the fistula is not clear, although Welisch and colleagues ${ }^{10}$ reported spontaneous closures in up to $39 \%$ of patients. Sherwood and colleagues ${ }^{11}$ advocated for a conservative approach for the management of asymptomatic fistulas. However, symptoms are more likely to occur with increasing age, especially in the second decade of life. ${ }^{12}$ Cheung and colleagues ${ }^{13}$ reported their experience with 3 patients who presented with only a cardiac murmur at the initial diagnosis but became symptomatic 3 to 5 years later. Moreover, an older age at diagnosis is associated with adverse surgical outcomes, including coronary thrombosis, myocardial infarction, and cardiomyopathy. ${ }^{14}$ Although the mortality and morbidity of surgery in pediatric patients approach zero, ${ }^{3,6,15}$ mortality increases with age in adult surgical patients. ${ }^{16}$ In this regard, Yim and colleagues ${ }^{6}$ advocate for early closure of the fistula before the age of 5 years to prevent the development of later complications, whereas Latson ${ }^{17}$ recommends the elective closure of the fistula, even if the patient has no symptoms, so long as the fistula remains clinically apparent after 3 to 5 years of observation. Some authors believe that significant clinical, ECG, and radiodiagnostic abnormalities should govern the decision for surgical repair, rather than symptomology., 3,15 However, the term "significant CAF" is not well defined. ${ }^{17,18}$ Our experience also demonstrates that the repair of ICCAFs in the pediatric population, at the time when there are significant clinical features without symptomology, is safe and can prevent complications. 

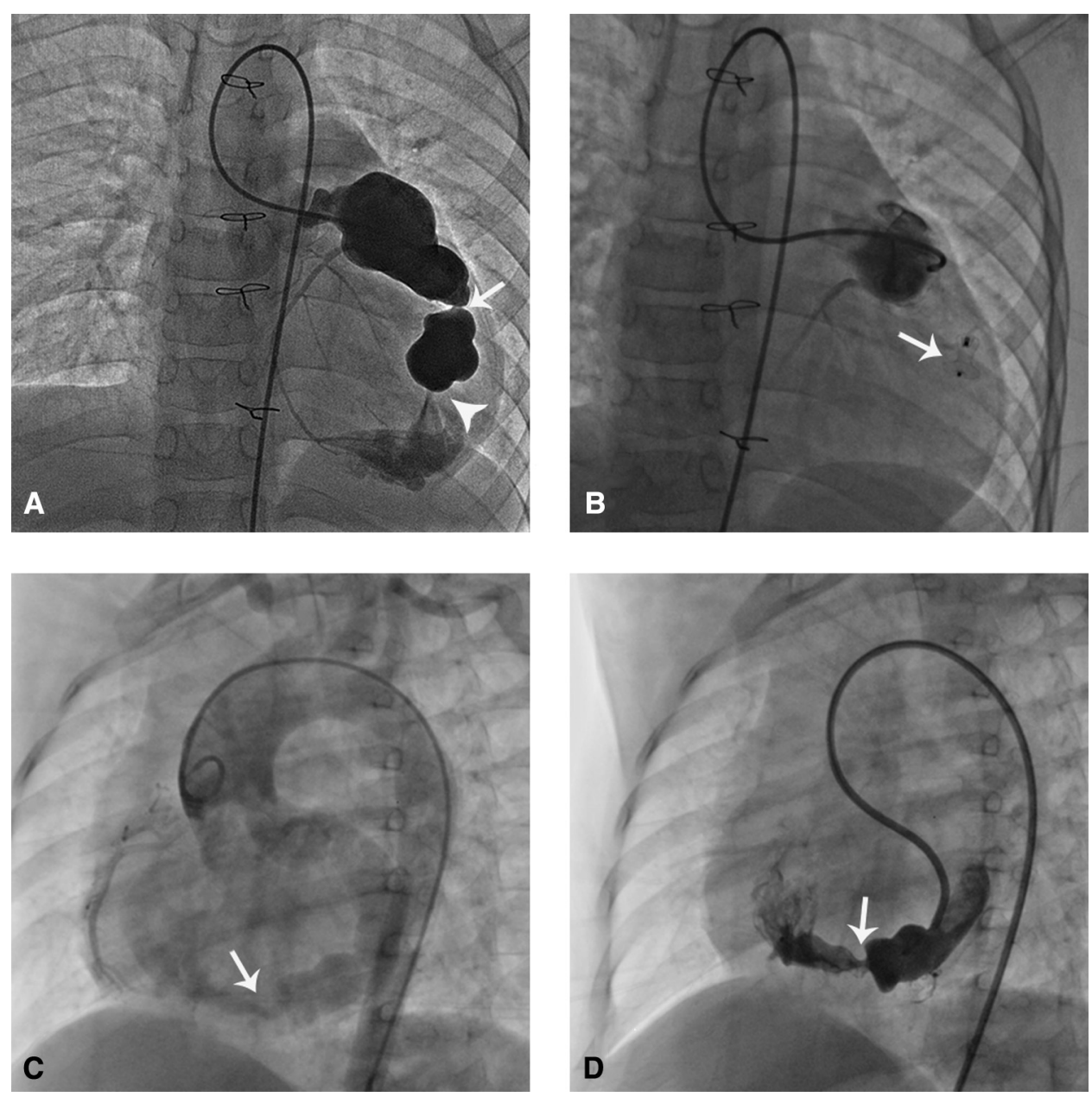

FIGURE 4. Catheter angiography and transcatheter closure for the residual shunt. The first patient: (A) Two aneurysmal dilations of the left anterior descending artery are identified connected by an isthmus portion (arrow), before entry into the apex of the RV (arrowhead). B, The residual shunt is obliterated by placing an Amplazter PDA occluder (AGA Medical Corp, Golden Valley, Minn) between the aneurysms. The second patient: (C) The dilated LCX artery drains into the RV (arrow). D, An Amplazter vascular plug (arrow) is placed distal to the coronary, but a trivial leak is identified after the procedure.

We recommend patients undergo surgical obliteration if the diameter of the fistula exceeds $3 \mathrm{~mm}$. If the patient has an aneurysmal dilation of the feeding coronary artery, an enlarged cardiac silhouette on chest x-ray, or a sign of ventricular hypertrophy on ECG, obliteration of the fistula also is recommended even if the diameter is less than $3 \mathrm{~mm}$.
Different surgical techniques vary according to the individual anatomy of the fistula. Epicardial ligation applies to a fistula that is oriented in a side-to-side fashion with a normal distal end, ${ }^{16}$ which can be confirmed by digital palpitation. Temporary occlusion test with ECG monitoring is required to prevent myocardial ischemia after ligation, although some authors reported the

TABLE 3. Recent literature on surgical repairs of coronary artery fistula in pediatric patients

\begin{tabular}{|c|c|c|c|c|c|}
\hline Authors and year published & Years of study & No. of patients & No. of ICCAF cases (\%) & $\begin{array}{c}\text { Mortality } \\
(\%)\end{array}$ & $\begin{array}{c}\text { Recanalization } \\
(\%)\end{array}$ \\
\hline Mavroudis and colleagues, ${ }^{3} 1997$ & 1968-1996 & 17 & $13(76)$ & 0 & 0 \\
\hline Holzer and colleagues, ${ }^{4} 2004$ & $1970-2004$ & 10 & $7(70)$ & 0 & 0 \\
\hline Malekahmadi and Shahmohammadi, ${ }^{5} 2005$ & $1990-2000$ & 10 & $9(90)$ & 0 & 0 \\
\hline Yim and colleagues, ${ }^{6} 2015$ & $1982-2012$ & 13 & $6(46)$ & 0 & 0 \\
\hline
\end{tabular}

Yim and colleagues, ${ }^{6} 2015$

13

6 (46)

ICCAF, Isolated congenital coronary artery fistula. 
occurrence of myocardial ischemia, even when the temporary occlusion test was negative. ${ }^{13}$ In contrast, no patients had transient ST-T changes after epicardial ligation in our series. We would perform a transcoronary approach if the feeding coronary is dilated and tortuous, with diffuse epicardial thrill, in which case epicardial ligation is not possible or concomitant arterioplasty is planned to remove the excess aneurysm wall. Okamura and colleagues ${ }^{15}$ reported that 3 of 6 patients who underwent the transcoronary procedure developed long-term coronary occlusions after surgery, and therefore advocated to consider this technique only when an alternative surgical approach could not be used. Because the direct vascular trauma may lead to thrombosis, we routinely prescribed antiplatelet therapy in patients after transcoronary closure with oral aspirin $(5 \mathrm{mg} / \mathrm{kg} / \mathrm{d})$ for 6 months. However, we did not prescribe antiplatelet therapy in patients after the other surgical techniques. Coronary thrombosis is more likely to occur in older children and in patients who have fistulas draining into the coronary sinus, ${ }^{6,14,19}$ which is not the case in our series. An intracardiac approach is considered when the fistula is inaccessible and drains into the posterior surface of the heart or no obvious dilation of the coronary artery can be identified. In this case, CPB is required and caution should be taken to temporarily occlude the fistula while administering cardioplegia after crossclamping the aorta. ${ }^{7}$ This approach is a relatively more complex procedure, and special attention should be paid to the adjacent structures, such as the valve apparatus.

There is no clear preference for one surgical technique over another. However, our results indicate that a residual shunt is more likely to occur after extracardiac repair, as already demonstrated by Cheung and colleagues, ${ }^{13}$ who also have advocated that the fistula should be closed within the cardiac chamber on the basis of this finding. The worldwide rate of the recanalization is variable, ranging from zero (Table 3) to as much as $50 \% .{ }^{20}$ Ponthier and colleagues ${ }^{20}$ found that the reintervention for residual shunt occurs later in pediatric patients. In our series, all recanalizations occurred within the first year after surgery, whereas 2 reinterventions were performed later at 1 year and 4 years after initial surgery. Thus, careful evaluation after surgery is required to detect the residual shunts promptly, especially in the early postoperative period after transcoronary repair. Hou and colleagues ${ }^{9}$ advocate that we should ignore fistulas less than $2 \mathrm{~mm}$ in diameter. Our experience to some extent suggests that residual shunts within $3 \mathrm{~mm}$ can be left free from reintervention. However, these should be carefully monitored during the follow-up period. Patients with aneurysmal dilation of the involved coronary should be managed more aggressively.
Recently, transcatheter closure of ICCAFs has become an alternative to surgical closure. Avoidance of scars and quicker recovery are theoretic advantages over traditional surgery ${ }^{17}$ However, this technique is not without complications. Device migration, ${ }^{20}$ thrombosis, ${ }^{21,22}$ and tricuspid valve injury ${ }^{23}$ have been reported in percutaneous series. Recanalization after the procedure also occurred at a degree that varied from trivial to large. ${ }^{21,24}$ Patient selection based on the anatomy of the fistula is a prerequisite for satisfactory transcatheter closure. Fistulas with a large size, multiple communications, and adjacent vessels at risk may be contraindications to transcatheter closure. $^{3}$ In our experience, if the feeding coronary artery gives rise to branches near the drainage site, the occluder would compromise the distal flow. If the feeding coronary artery is extremely tortuous, the guide wire would not be able to advance through the fistulous track. Diffuse or multiple fistulas would be more suitable for surgical obliteration because all fistulous tracks can be closed by opening the cardiac chamber or by ligating all of the feeding vessels. ${ }^{7}$ Surgery also is preferred if the feeding coronary artery has an aneurysm that needs concomitant arterioplasty to remove the excess wall. ${ }^{16}$ In addition, it would be difficult to perform catheter intervention considering the relatively small vessels in the pediatric population, especially at a very young age. ${ }^{3,6}$ Wang and colleagues ${ }^{23}$ described percutaneous closure failures in 5 patients $(13.5 \%)$, due to low body weights, large fistulas, coronary tortuosity, or occlusion of distal blood flow. ${ }^{23}$ Surgical intervention would be a better choice when the patient age or the anatomy of the fistula is not suitable for transcatheter closure.

\section{Study Limitations}

This is a retrospective study in pediatric patients with a relatively short follow-up in a single institution. Longerterm studies in cooperation with adult institutions are needed to follow the complete history of patients after surgical closure. Further collaborative, prospective, and randomized studies involving patients undergoing surgery, transcatheter closure, or conservative therapy will be needed to assess the specific benefits of different approaches.

\section{CONCLUSIONS}

Our experience demonstrates that surgical repair of ICCAFs in pediatric patients can be performed with low mortality and morbidity. However, careful evaluation after surgery is necessary to monitor any residual shunts.

\section{Conflict of Interest Statement}

Authors have nothing to disclose with regard to commercial support. 


\section{References}

1. Tuo G, Marasini M, Brunelli C, Zannini L, Balbi M. Incidence and clinical relevance of primary congenital anomalies of the coronary arteries in children and adults. Cardiol Young. 2013;23:381-6.

2. Biorck G, Crafoord C. Arteriovenous aneurysm on the pulmonary artery simulating patent ductus arteriosus botalli. Thorax. 1947;2:65-74.

3. Mavroudis C, Backer CL, Rocchini AP, Muster AJ, Gevitz M. Coronary artery fistulas in infants and children: a surgical review and discussion of coil embolization. Ann Thorac Surg. 1997;63:1235-42.

4. Holzer R, Johnson R, Ciotti G, Pozzi M, Kitchiner D. Review of an institutional experience of coronary arterial fistulas in childhood set in context of review of the literature. Cardiol Young. 2004;14:380-5.

5. Malekahmadi M, Shahmohammadi A. Surgical outcome of coronary artery fistulas repair in children. Pediatr Cardiol. 2005;26:328-30.

6. Yim D, Yong MS, d'Udekem Y, Brizard CP, Konstantinov IE. Early surgical repair of the coronary artery fistulae in children: 30 years of experience. Ann Thorac Surg. 2015;100:188-94.

7. Mangukia CV. Coronary artery fistula. Ann Thorac Surg. 2012;93: 2084-92.

8. Kamiya H, Yasuda T, Nagamine H, Sakakibara N, Nishida S, Kawasuji M, et al. Surgical treatment of congenital coronary artery fistulas: 27 years' experience and a review of the literature. J Card Surg. 2002;17:173-7.

9. Hou B, Ma WG, Zhang J, Du M, Sun HS, Xu JP, et al. Surgical management of left circumflex coronary artery fistula: a 25-year single-center experience in 29 patients. Ann Thorac Surg. 2014;97:530-6.

10. Welisch E, Norozi K, Burrill L, Rauch R. Small coronary artery fistulae in childhood: a 6-year experience of 31 cases in a tertiary paediatric cardiac centre. Cardiol Young. 2016;26:738-42.

11. Sherwood MC, Rockenmacher S, Colan SD, Geva T. Prognostic significance of clinically silent coronary artery fistulas. Am J Cardiol. 1999;83: 407-11.

12. Liberthson RR, Sagar K, Berkoben JP, Weintraub RM, Levine FH. Congenital coronary arteriovenous fistula. Report of 13 patients, review of the literature and delineation of management. Circulation. 1979;59:849-54.

13. Cheung DL, Au WK, Cheung HH, Chiu CS, Lee WT. Coronary artery fistulas: long-term results of surgical correction. Ann Thorac Surg. 2001; 71:190-5.
14. Valente AM, Lock JE, Gauvreau K, Rodriguez-Huertas E, Joyce C, Armsby L, et al. Predictors of long-term adverse outcomes in patients with congenital coronary artery fistulae. Circ Cardiovasc Interv. 2010;3:134-9.

15. Okamura T, Nagashima M, Yamada Y, Hiramatsu T, Yamazaki K. Effective long-term surgical management of congenital coronary artery fistulas. Tohoku J Exp Med. 2011;223:205-9.

16. Said SM, Burkhart HM, Schaff HV, Connolly HM, Phillips SD, Suri RM, et al. Late outcome of repair of congenital coronary artery fistulas-a word of caution. J Thorac Cardiovasc Surg. 2013;145:455-60.

17. Latson LA. Coronary artery fistulas: how to manage them. Catheter Cardiovasc Interv. 2007;70:110-6.

18. Armsby LR, Keane JF, Sherwood MC, Forbess JM, Perry SB, Lock JE. Management of coronary artery fistulae. Patient selection and results of transcatheter closure. J Am Coll Cardiol. 2002;39:1026-32.

19. Gowda ST, Latson LA, Kutty S, Prieto LR. Intermediate to long-term outcome following congenital coronary artery fistulae closure with focus on thrombus formation. Am J Cardiol. 2011;107:302-8.

20. Ponthier L, Brenot P, Lambert V, Petit J, Riou JY, Baruteau AE. Closure of isolated congenital coronary artery fistula: long-term outcomes and rate of re-intervention. Pediatr Cardiol. 2015;36:1728-34.

21. Jama A, Barsoum M, Bjarnason H, Holmes DR Jr, Rihal CS. Percutaneous closure of congenital coronary artery fistulae: results and angiographic follow-up. JACC Cardiovasc Interv. 2011;4:814-21.

22. Gowda ST, Forbes TJ, Singh H, Kovach JA, Prieto L, Latson LA, et al. Remodeling and thrombosis following closure of coronary artery fistula with review of management: large distal coronary artery fistula-to close or not to close? Catheter Cardiovasc Interv. 2013;82:132-42.

23. Wang SS, Zhang ZW, Qian MY, Zhuang J, Zeng GH. Transcatheter closure of coronary arterial fistula in children and adolescents. Pediatr Int. 2014;56:173-9.

24. Zhu XY, Zhang DZ, Han XM, Cui CS, Sheng XT, Wang QG, et al. Transcatheter closure of congenital coronary artery fistulae: immediate and long-term follow-up results. Clin Cardiol. 2009;32:506-12.

Key Words: coronary artery fistula, surgery, pediatric patients 

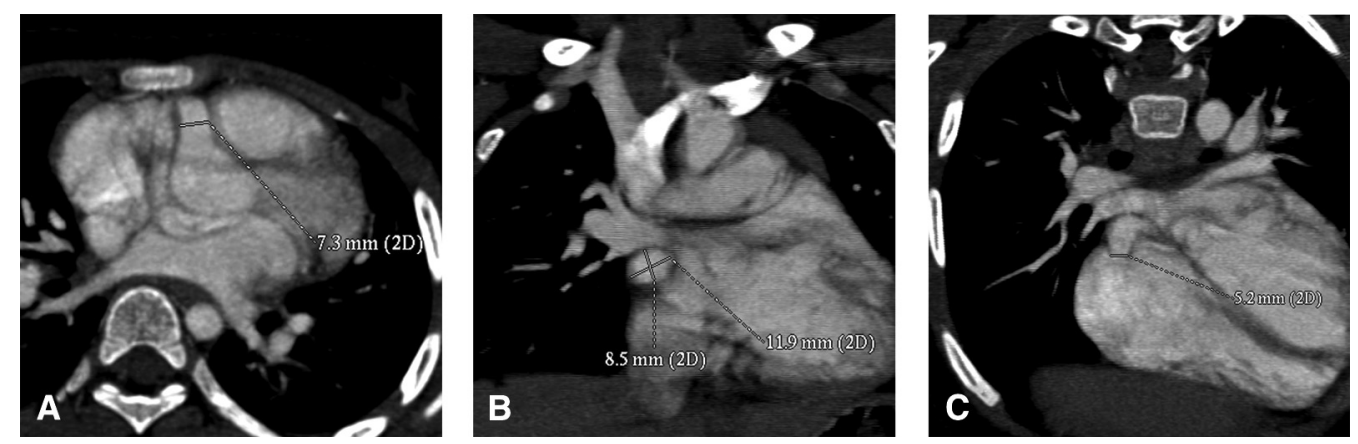

FIGURE E1. Example of an RCA to right atrium fistula detected by multidetector computed tomography with maximum intensity projection reconstruction. A, Dilation of the RCA with a diameter of $7.3 \mathrm{~mm}$ at the origin. B, The enlarged RCA travels along the right atrioventricular groove. $\mathrm{C}$, The RCA terminates in the RA with a diameter of $5.2 \mathrm{~mm}$. 